\title{
INTERFERÊNCIA EM LARGA ESCALA ENTRE ESTRUTURAS COMPRESSIVAS E DISTENSIVAS: EXEMPLO DO APPENNINO SETENTRIONAL, ITÁLIA.
}

\author{
LUIGICARMIGNANI*, ALBERTO PIO FIORI** \& PAULO CESAR SOARES**
}

\begin{abstract}
LARGE-SCALE COMPRESSIONAL AND EXTENSIONAL STRUCTURES: THE NORTHERN APPENNINE EXAMPLE (ITALY). In the Northern Apennines, the tectonic window of the Apuanes Alps provides an exceptionally clear exposure of the interference geometry between the structures of the Tertiary collisional tectonics and the following extensional phase. Collisional tectonics began in the Upper Oligocene, extension in the Miocene, and both occur at mid-crustal levels.

The collisional phase is characterised by sin-metamorphic foliation, the axial plane schistosity of non-cylindrical folds, often sheath-shaped. A widespread stretching lineation is also present, trending NE-SW; the tectonic transport is directed towards NE.

In the lower levels of the Apuan Metamorphic Complex extension began in metamorphic conditions with extensional shear bands. Location of these features is controlled by the structure realised in the previous collisional phase, whose structures and structural elements were refolded in a km-scale antiform.

Two types of folds are associated with extensional shear bands: a) "passive simple shear folds", originated in correspondence of attitude and dip variation of bedding and foliation, inherited by the compressive phase and amplified in the late simple shear bands up to overturned folds; $b$ ) "transfer folds", originated by stress oriented parallel to the deformed levels at the tip zones of detachment horizons.

This types of folds occur at the mesoscopic as well as at kilometric scale; examples of both are described in this work.
\end{abstract}

Keywords: Interference structures; geodinamic models; distensive and compressive tectonism; convergence and collision; metamorphic complex.

RESUMO A superposição de processos tectônicos extensionais sobre estruturas compressionais tem sido descrita com certa freqüência em cinturões orogênicos, mais raramente no Brasil, e a geometria final destas estruturas superpostas, em geral, apresenta elevada complexidade. Na parte norte dos Appenninos (Itália), a janela tectônica dos Alpes Apuane (Núcleo Metamórfico dos Alpes Apuane), fornece uma exposição excepcionalmente clara de estruturas de interferência entre tectônica compressiva oligocênica, associada à colisão da Placa Adriática com a Placa Ibérica, e a subsequente tectônica distensiva miocênica, associada a abertura do mar Tirreno setentrional. A fase colisional e caracterizada por uma xistosidâde plano-axial, associada a dobras não cilíndricas, freqüentemente em forma de bainha. Lineações de estiramento bem desenvolvidas se fazem presente, direcionadas para NE-SW, com sentido de transporte para nordeste.

Nos níveis inferiores do Complexo Metamórfico dos Alpes Apuane, a extensão se deu em condições metamórfícas, associada a zonas de cisalhamento. O posicionamento dessas zonas é controlado por estruturas formadas na fase colisional antecedente, redobradas agora, em escala quilométrica.

Dois tipos de dobras ocorrem associados às zonas de cisalhamento extensionais: a) dobras passivas, originadas por cisalhamento simples, nucleadas a partir das heterogeneidades do acamamento e foliação, herdadas da fase compressiva, e gradativamente amplificadas nas zonas de cisalhamento tardias, até a inversão de flancos, e b) dobras originadas por esforços orientados paralelamente aos níveis deformados, associadas a terminações de horizontes de descolamento.

Esses dois tipos de dobras ocorrem tanto em escala mesoscópica como à escala quilométrica; exemplos de ambos são descritos no presente trab-Jho

Palavras-chaves: Estruturas de interferência; modelos geodinãmicos; tectônica distensiva e compressiva; convergência e colisão continental; complexos e núcleos metamórficos.

INTRODUÇÃO O Appennino Setentrional (Fig. 1) constitui uma cadeia orogênica terciária, cuja estruturação é devida à superposição de uma importante tectônica extensional miocênica, sobre uma tectônica compressiva devida à convergência e colisão entre a Placa Ibérica e a Placa Adriática, do Neocretáceo ao Oligoceno (Fig. 2). A partir do Mioceno, a deformação compressiva avança do ocidente para o oriente, através da península italiana, até atingir o Mar Adriático (Merla 1952). Contemporaneamente, na parte interna da cadeia, as estruturas contracionais foram afetadas por uma importante tectônica extensional (Fig. 3), cuja intensidade aumenta de norte para sul. Na Toscana meridional, estruturas do tipo horst e graben, do Neomioceno, Plioceno e Pleistoceno, estão associadas a vulcanismo (Fig.l), desenvolvendo uma estrutura análoga àquela descrita para a Província Basin-and-Range da América do Norte (Bertini et al 1991, Carmignani et al., 1993).

Atualmente, o regime extensional afeta toda a vertente ocidental da cadeia, enquanto o regime compressi vo chega até o Adriático e à Bacia do Pó. A presença, por longo tempo e em um mesmo perfil transversal, de extensão na parte interna da cadeia e contração na parte externa, que migraram juntas em direção ao antepaís, é uma das características mais marcantes e problemáticas do Appennino (Elter et al. 1975).

A contemporaneidade da tectônica compressiva e extensional foi interpretada através de diferentes modelos geodinãmicos, a saber:

a) Um primeiro modelo prevê que a extensão da parte interna da cadeia esteja ligada à abertura do mar Tirreno, na forma de uma bacia de retroarco a partir do Mioceno médio -Neomioceno. A contração, ainda ativa ao longo da margem externa da cadeia, é atribuída à subducção da litosfera ao longo da margem oriental da cadeia (Boccaletti \& Guazzone 1974, Scandone 1979).

b) Um segundo modelo prevê a abertura do mar Tirreno como conseqüência do levantamento de um diápiro do manto. A translação gravitacional da crosta em direção à periferia do domo astenosférico determinaria as condições de extensão na zona interna da cadeia e compressão na zona externa (Van Bemmelen 1972, Wezel 1982, Locardi 1982). Lavecchia (1988) propõe que o adelgaçamento da crosta tirrênica é

* - Dipartimento di Scienze delia Terra, Università di Siena. Via delle Cerchia, 3, 51100 Siena, Italy. E-Mail: Iuigi@sidst4.dst.unisi.it ** - Departamento de Geologia, Universidade Federal do Paraná. Caixa Postal 19.011,81.531-990-Curitiba, PR - Brasil. E-Mail: fiori@ setuva.geologia.ufpr.br, soares@ setuva.geologia.ufpr.br 


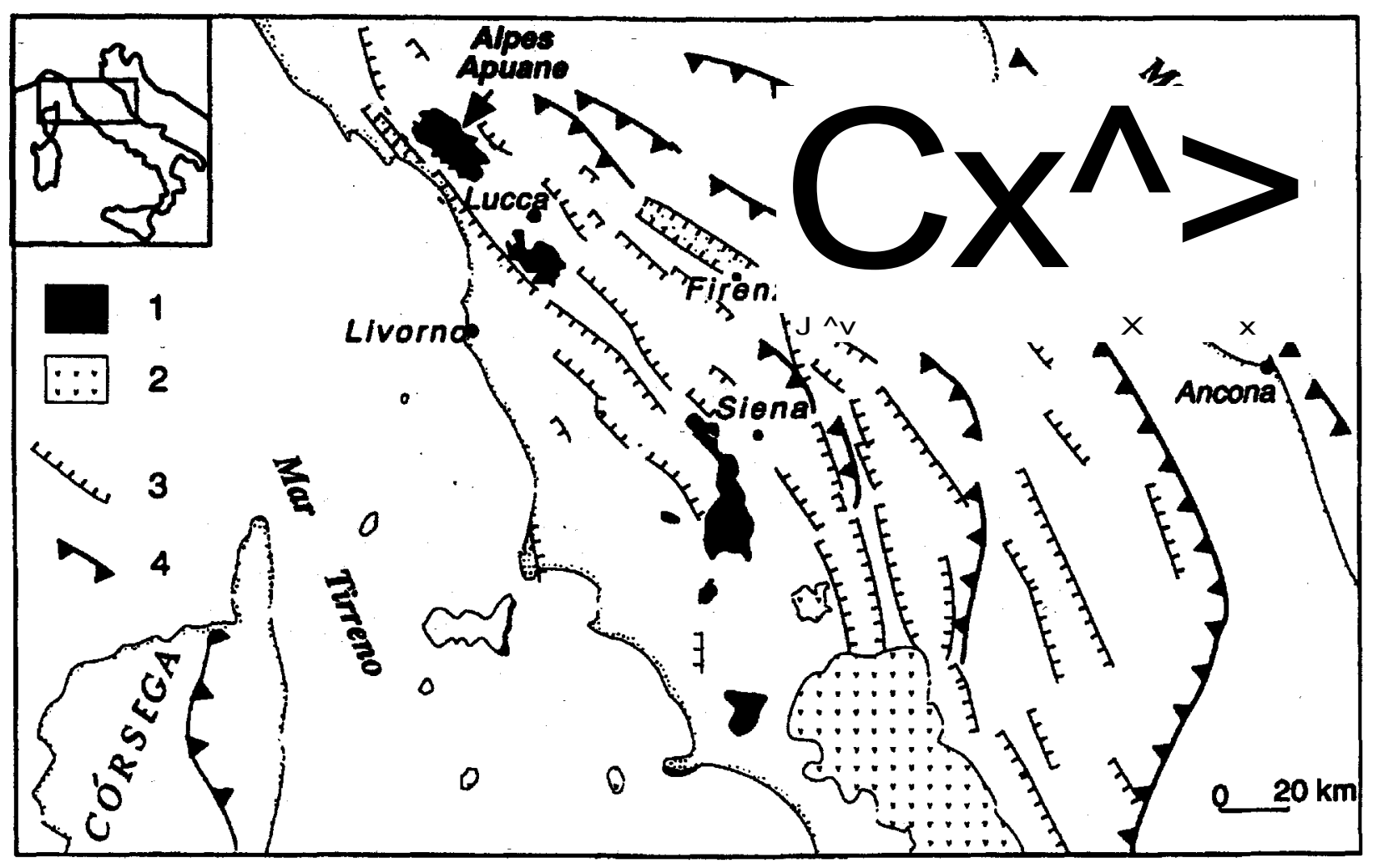

Figura 1 - Esquema estrutural do Appennino setentrional 1: Complexo Metamórfico Toscano; 2: Rochas vulcânicas terciárías; 3: Falhas normais principais. 4: Cavalgamentos principais.

Figure 1 - Tectonic sketch map of the Northern Apennines. 1: Tuscan Metamorphic Complex, 2: Tertiary volcanic rocks, 3: Major extensional faults, 4:.Major thrusts

responsável pela translação de elementos crustais em direção a leste, com contração na frente e extensão atrás.

c) Em um modelo mais recente, a migração da extensão e da contração, de oeste para leste, é atribuída à delaminação e afundamento do manto litosférico da Placa Adriática, após a colisão continental, a partir da zona de sutura (Malinverno \& Ryan 1986, Royden et al. 1987, Patacca \& Scandone 1989, Serri et al. 1991).

A discussão do modelo geodinâmico que determinou a migração do sistema cadeia-antefossa em direção ao antepaís, e a contemporaneidade de esforços extensionais e contracionais, ainda está aberta, mesmo que, no geral, seja aceito que toda a zona interna da Cadeia do Appennino tenha sofrido, durante o Mioceno, mudança de um regime compressivo sin-colisional a um regime distensivo, ocasionando a exumação dos metamorfitos e intrusão de granitóides da margem tirrênica da cadeia. Esta evolução faz do Appennino setentrional uma área privilegiada para o estudo de estruturas derivadas de inversões tectônicas. O objetivo deste trabalho é, pois, a discussão de duas dessas estruturas, de dimensões quilométricas, presentes nos metamorfitos de baixo grau dos Alpes Apuanes que, segundo os autores, encontram eco em outras cadeias terciárias e paleozóicas européias e, muito provavelmente, constitui um aspecto geral das cadeias colisionais.

QUADRO REGIONAL O Appennino setentrional é uma cadeia constituída por fatias tectônicas terciárias, originadas quando da colisão entre a paleomargem Ibérica e a Placa Adriática (Figs. 2 e 3). A colisão determinou a sobreposição de parte do embasamento e das coberturas oceânicas sobre a paleomargem continental da Placa Adriática.
Na reconstituição paleogeográfica do Appennino setentrional são tradicionalmente assinalados, da parte interna para a parte externa, os seguintes domínios (Fig. 4):

- Domínio Ligure, que compreende um embasamento oceânico e suas coberturas sedimentares pelágicas do Neo-Jurássico - Paleo-Cretáceo e flysch cretáceo-eocênicos, descolados do seu substrato e que constituem uma melange com elementos ofiolíticos.

- Domínio Subligure, que é representado somente por uma sucessão paleozoico-mesozóica, intensamente tectonizada, da qual não se conhece sua amplitude original, nem a natureza de seu substrato, e sedimentada sobre uma área de transição entre crosta oceânica do Domínio Ligure e o substrato continental do Domínio Toscano.

- Domínio Toscano, que compreende sedimentos pertencentes à margem continental Adriática, sendo representado por unidades tectônicas deformadas em diferentes níveis estruturais:

a - Nappe Toscana, que compreende formações anquimetamórficas a não metamórficas, com idades entre o Triássico e o Mioceno, descolada no nível dos evaporitos do Neotriássico; b - Complexo Metamórfico Toscano, constituído por varias unidades tectônicas com metamorfismo na fácies xisto verde. Compreende também parte do embasamento hercínico.

- Domínio Umbro - Marchigiano, que é representado por uma sucessão mesozóica-terciária, descolada ao nível dos evaporitos triássicos. Apresenta-se dobrado e falhado e aflora nas regiões da Umbria e Marches; mais a norte, é recoberto pelas unidades do Domínio Ligure. Representa a zona mais externa do cinturão, com uma sucessão sedimentar que alcança o Neomioceno.

Depois da colisão continental na parte interna da cadeia (Toscana), as estruturas contracionais foram afetadas por uma 

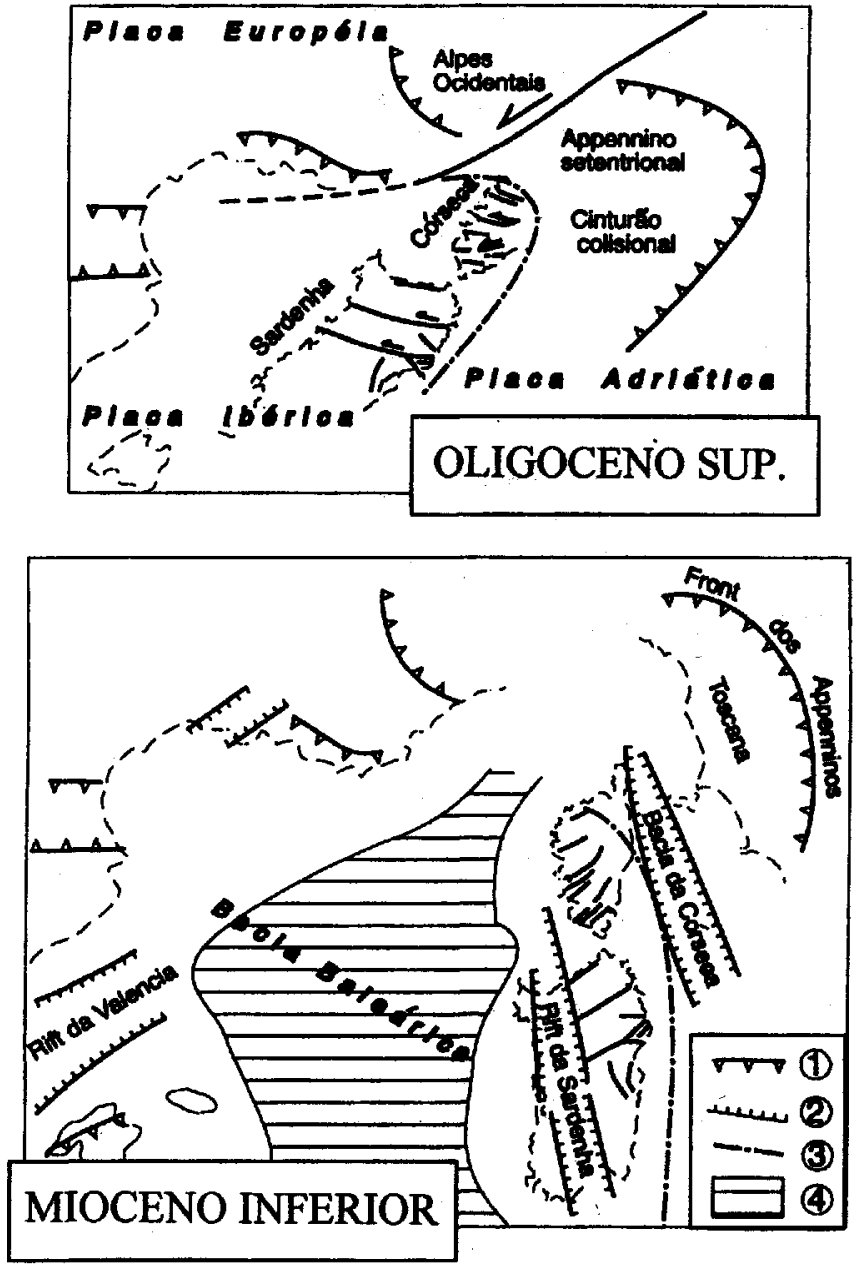

Figura 2. Na parte superior: distribuição das placas no Neo-Oligoceno; a litosfera da Sardenha e da Córsega é considerada como parte da Placa Ibérica, em colisão com a Placa Adriático, originando o cinturão colisional do Appennino setentrional. Na parte inferior: abertura da Bacia Balearica, do rift da Sardenha e da Bacia da Córsega. Figure 2.- Top: plate tectonic setting during the Late Oligocene; the Corsica-Sardinia massif is interpreted as part of the Iberian plate which collides with the Adriatic microplate, originating the Northern Apennines collisional belt. Bottom: opening of the Balearic basin, the Sardinian rift and the Corsica basin.

importante tectônica distensiva, cuja intensidade aumenta de norte para sul. Na Toscana meridional, a fase principal é do Meso-Mioceno, sendo caracterizada por falhas extensionais de baixo ângulo que culminaram com a sobreposição das unidades mais elevadas do edifício de nappes ou fatias tectônicas sobre as rochas metamórficas da margem continental (Complexo Metamórfico Toscano). Posteriormente, estruturas do tipo horst e graben, do Mioceno-Neopleistoceno, que se prolongam para a Toscana setentrional, associam-se a eventos vulcânicos, cortando as estruturas contracionais e extensionais precedentes. Atualmente, estruturas extensionais afetam a parte ocidental do Appennino, enquanto as contracionais afetam a margem externa da cadeia, ao longo da Planície do Pó e o Mar Adriático (Fig. 1).
COMPLEXO METAMÓRFICO TOSCANO

Nos

Alpes Apuanes (Fig. 1), aflora a mais completa sucessão das unidades tectônicas do Appennino setentrional, sendo considerada uma região chave para a interpretação da estruturação e evolução desta cadeia. O Complexo Metamórfico Toscano (Figs. 5 e 6) aflora em uma grande janela tectônica, sendo tradicionalmente subdividido em:

-"Unidade de Massa, que compreende as formações paleozóicas e triássicas aflorantes na margem sul-ocidental do maciço, e

-"Autóctone", aflorante nos setores central e norte-oriental da janela, compreendendo a parte mais profunda do complexo metamórfico.

Esta janela é um dos melhores exemplos de superposição direta de unidades tectônicas de níveis crustais superiores sobre um complexo metamórfico intensamente deformado, em um nível crustal médio.

No Complexo Metamórfico Toscano são reconhecidos os dois principais eventos deformativos do Appennino setentrional (Carmignani et al. 1980, Carmignani \& Kligfield 1990), ou seja:

1) Uma deformação compressiva dúctil $\left(\mathrm{D}_{1}\right)$, ligada à colisão continental da Placa Ibérica com a Placa Adriática. Tanto o embasamento como a cobertura desta ultima são deformados e metamorfisados (fácies xisto verde, \pm biotita, \pm cianita), a partir do Neo-Oligoceno, por zonas de cisalhamento com transporte para nordeste. Dessa forma, a Placa Adriática passa a ser cavalgada pela Nappe Toscana, com metamorfísmo predominantemente anquizonal (Cerrina Feroni et al. 1983) e pelo Domínio Ligure (Fig. 7 A, B, C).

2) Uma deformação distensiva dúctil $D_{2}$ que, a partir do Paleomioceno, conduz ao progressivo reequilibrio isostático da crosta espessada, através de denudação tectônica combinada com erosão (Fig. 7 D, E).

A paragênese sincinemática da fase $D_{1}$ é constituída por micas claras (muscovita, paragonita e pirofilita), biotita, clorita, quartzo e feldspatos. Durante os primeiros estádios do desenvolvimento da fase $\mathrm{D}_{2}$, ocorreu a cristalização de cloritóide e epídoto no "Autóctone" e, de cianita, cloritóide e epídoto na Unidade de Massa. Em seguida, durante os últimos estádios de desenvolvimento da xistosidade tardia, verifica-se nova cristalização de micas claras potássicas e clorita, com parcial recristalização de carbonato.

A partir da distribuição da pirofilita, da cianita e das temperaturas de metamorfismo, estimadas através do geotermômetro calcita-dolomita nos mármores ( $\mathrm{D}_{1}$ Pisa et al. 1985), observa-se um incremento do grau metamórfico na parte interna do "Autóctone", procedendo das zonas orientais em direção às zonas ocidentais.

A tectônica distensiva pós-colisional dá origem a uma estrutura do tipo core complex na qual, com referência à terminologia norte americana (Davis 1980, Coney \& Harms 1984, Malavielle 1987, Lister \& Davis 1989), o Complexo Metamórfico Toscano representa a Placa inferior enquanto a Nappe Toscana e o Domínio Ligure constituem a placa superior. A falha de descolamento basal, de natureza distensiva (extensional detachment fault) é marcada pela Formação Calcare Cavernoso (base da Nappe Toscana), que constitui um horizonte contínuo de cataclasitos. Este horizonte funcionou, na realidade, como falha de cavalgamento com transporte para nordeste, no Neo-Oligoceno, durante a tectônica compressiva, e como falha extensional, do Paleomioceno em diante (Carmignani \& Kligfield 1990)

TECTÔNICA COMPRESSIVA Di A fase $\mathrm{D}_{1}$, é caracterizada por uma xistosidade sin-metamorfica $S_{1}$ associada a uma lineação de estiramento $\mathrm{L}_{1}$ orientada nordeste-sudoeste, bem desenvolvida em quase todas as formações metamórficas. A foliação é paralela ao plano axial de dobras isoclinais, 


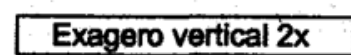

$0 \mathrm{Km}$
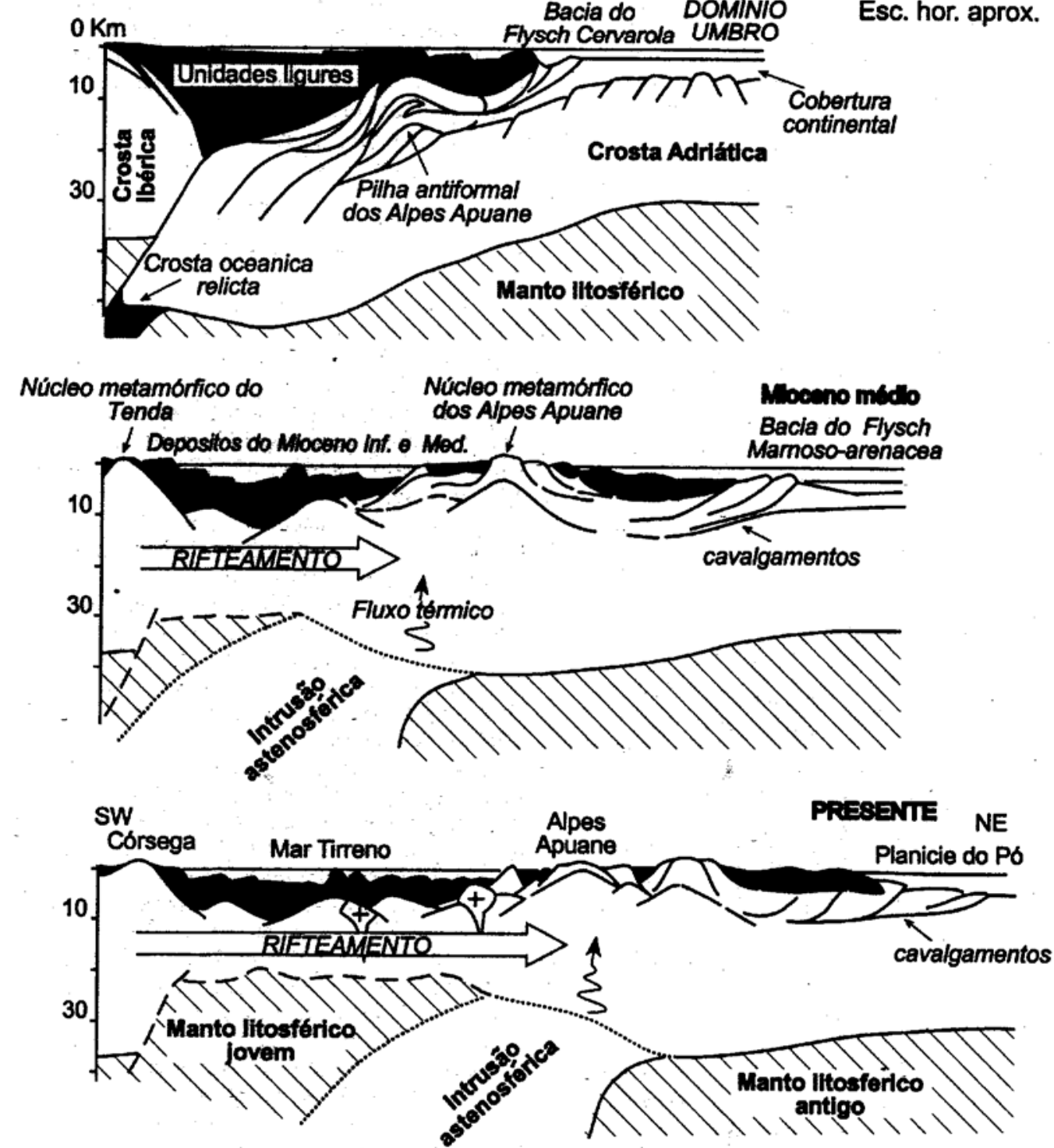

Figura 3 - Evolução esquemática do Appennino Setentrional Oligoceno Superior: colisão continental; desenvolvimento de uma pilha antiformal por rápido acavalamento e espessamento do prisma acrescionário. Mioceno: extensão na parte interna da cadeia colisional do Appennino setentrional; início de uma tectônica distensiva com deformação dúctil na crosta media e com deformação rúptil na crosta superior; na figura, a migração para leste da tectônica distensiva e do sistema do cinturão de cavalgamento-bacia de antepaís é atribuido a rifteamento, junto com a delaminação litosférica, o efeito da sobrecarga topográfica e fluxo térmico através da janela astenosférica (asthenospheric window)

Figure 3 - Schematic evolution of the Northern Apennines. Late Oligocene: end of the continental collision; development of the antiformal stack geometry by rapid underplating and thickening of the accretionary wedge. Miocene : extension in the inner part of the Northern Apennines; initiation of tectonic extension results in simultaneous ductile extension at middle crustal levels and brittle extension in upper crustal levels; the eastward migration of extensional tectonics and of the thrust belt-forcdeep-foreland system is attributed to rifting, together with the lithospheric delamination, the effect of the topographic load and the thermal flux transmitted through the asthenospheric window.

geralmente em forma de bainhas (sheath folds), A distorção interna (strain) é muito pronunciada em todos os litotipos, com exceção dos dolomitos triássicos, que respondem ao estiramento com boudinage, à escala da inteira formação.

$\mathrm{O}$ encurtamento progressivo levou ao desenvolvimento de um pilha antiformal (antiformal stack) cujo teto está em contato tectônico com a base da Nappe Toscana, enquanto o muro é constituído por um contato tectônico (não aflorante) que descola a cobertura dos Alpes Apuanes de seu embasamento (Fig. 7B e C). O empilhamento tectônico das coberturas sob o complexo apuano poderia ter dado origem à distensão na parte superior da pilha orogênica (Platt 1986), já no Paleo-Mioceno (Fig. 7C).

TECTÔNICA DISTENSIVA $\mathbf{D}_{2}$ A de extensão do Complexo Metamorfíco ocorreu segundo zonas de cisa- 


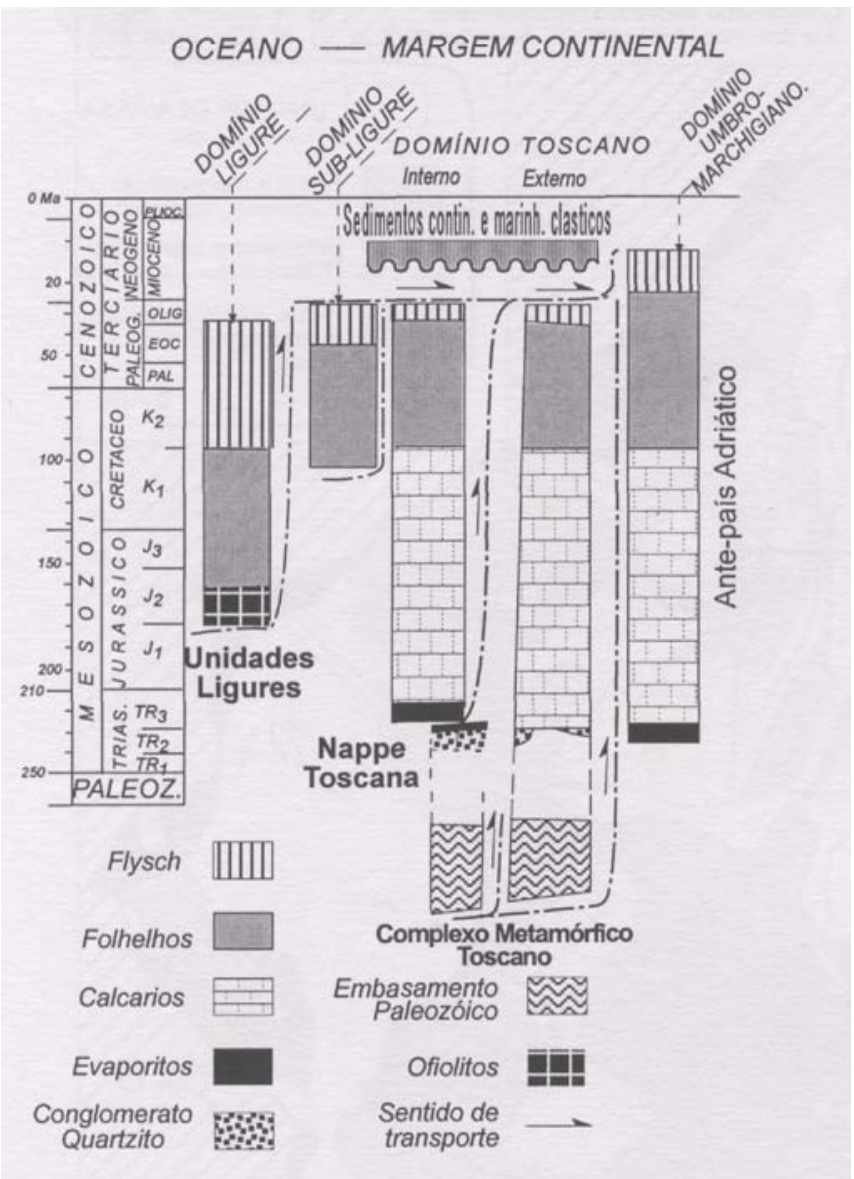

Figura 4 - Seqüencias estratigráficas das principais unidades tectônicas do Appennino setentrional.

Figure 4 - Stratigraphic sequences in the main tectonic units of the Northern Apennines.

lhamento dúcteis inclinadas para sudoeste, no flanco sul-ocidental e, para nordeste, no flanco norte-oriental do core complex.

O deslocamento entre as zonas de cisalhamento, inclinadas para sudoeste e para nordeste é, respectivamente, para sudoeste e nordeste (Figs. 5 e 6); à escala regional, esses movimentos determinam uma extensão horizontal acompanhada de adelgaçamento crustal.

A localização das zonas de cisalhamento extensionais é determinada pelas atitude da xistosidade $S_{1}$ e dos cavalgamentos na pilha antiformal da fase compressiva (Fig. 7 C, D): as zonas de cisalhamento inclinadas para sudoeste se desenvolvem principalmente onde a xistosidade da fase compressiva era inclinada para sudoeste (vertente tirrênica do Complexo Metamórfico), enquanto o sistema inclinado para nordeste desenvolve-se principalmente ao longo da vertente norte-oriental, onde a xistosidade era inclinada para nordeste.

Os minerais sintectônicos em relação à fase $\mathrm{D}_{1}$ compreendem muscovita ou fengita, biotita, clorita e quartzo. Durante a fase $D_{2}$ cristalizaram a fengita ou a clorita. A cianita e o cloritóide são pós-tectônicos em relação à fase $\mathrm{D}_{1}$ e sintectônicos ao início da fase $\mathrm{D}_{2}$ (Boccaletti \& Gosso 1980) sugerindo um pico térmico posterior à fase Di e contemporâneo ao início da fase $\mathrm{D}_{2}$. As idades K-Ar e ${ }^{40} \mathrm{Ar} /{ }^{39} \mathrm{Ar}$ da $12 \mathrm{Ma}$, obtidas para o fechamento das micas da fase $\mathrm{D}_{2}$ (Giglia \& Radicali di Braozolo 1970, Kligfield et al. 1986), indicam que a extensão dúctil do complexo Metamórfico iniciou no Mioceno médio e a uma profundidade crustal de 8 a $10 \mathrm{Km}$, antes da sua denudação e soerguimento.

DOBRAS DO REGIME DISTENSIVO O sentido de movimento da componente de cisalhamento simples associada à tectônica distensiva pode ser constatado através de vários indicadores cinemáticos (Simpson \& Schmid 1983, Simpson 1986), tais como clivagem de crenulação distensiva (Platt \& Vissers, 1980), bookshelf structure, relações entre porfiroblastos e suas sombras de pressão, relações entre superfícies de cisalhamento e xistosidade em milonitos S/C, (Berthé et al. 1979). Todavia, o indicador cinemático mais comum é a assimetria das dobras menores associadas às zonas de cisalhamento.

Uma das características fundamentais da tectônica dúctil distensiva é a grande heterogeneidade da deformação cisaIhante. O grau de distorção interna (strain), avaliado em função do grau de desenvolvimento da xistosidade $S_{2}$ e pela freqüência e ângulo de abertura das dobras menores, mostra que o mesmo é claramente relacionado à competência das formações afetadas (Carmignani et al. 1993).

As partes basais (filitos paleozóicos) e as superiores (sucessão pelítica, pelítico-carbonática e pelítico-arenosa cretácico-oligocênica) são constituídas por formações que, durante a fase distensiva, sofreram uma forte movimentação por extensão interna. As duas partes são separadas por um pacote dolomítico do Neotriássico, com potência de varias centenas de metros e caracterizado por uma deformação interna pequena ou mesmo ausente. A tectônica de dobras isoclinais com planos axiais sub-horizontais da fase $\mathrm{D}_{1}$ determina um empilhamento de formações com alternância de reologias contrastantes. Sobre esta pilha, a fase distensiva $\mathrm{D}_{2}$ levou à formação de um edifício estrutural complexo, marcado por grande heterogeneidade da deformação interna.

As estruturas mais comuns e típicas das zonas com deformação distensiva dúctil são dobras intrafoliares, geralmente assimétricas. A nível de mesoescala, as dobras da fase $\mathrm{D}_{2}$ têm eixos direcionados entre norte-sul e noroeste-sudeste e sentido de mergulho do plano axial em direção aos quadrantes orientais e ocidentais, respectivamente, sobre as vertentes oriental e ocidental do core complex. As dobras $\mathrm{D}_{2}$ são quilométricas e representam um bom exemplo de encurtamento de camadas em grande escala, sob regime crustal distensivo. As mesmas oferecem uma interessante contribuição ao entendimento de um problema mais geral, acerca dos mecanismos de desenvolvimento de dobras inversas de grandes dimensões.

Serão consideradas a seguir, duas zonas dos Alpes Apuanes, nas quais a estrutura da fase colisional é deformada por dobras quilométricas inversas: as estruturas do vale do Arni e do alto vale do Rio Frígido (Fig. 5 e 6). Ambas pertencem ao flanco ocidental do core complex e as estruturas sin- $\mathrm{D}_{1}$, com transporte para nordeste, são deformadas por estruturas sin$\mathrm{D}_{2}$, com transporte para sudoeste. Nestas duas áreas estão bem representados os dois tipos fundamentais de mecanismos de dobramento associados à distensão, reconhecidos nos Alpes Apuanes (Carmignani et al. 1993).

A estrutura do Vale do Arni Os elementos essenciais da sucessão estratigráfica e da estrutura do vale do Arni estão ilustrados na figura 8 . A estrutura fundamental da fase $\mathrm{D}_{1}$ é representada por duas sinclinais isoclinais principais: a Sinclinal do Arni e a Sinclinal do Monte Fiocca, separadas pela Anticlinal do Passo Sella. Sobre os mármores liássicos do flanco inverso da Sinclinal do Arni aparece diretamente o embasamento paleozóico, através de contato tectônico (Cavalgamento do Monte Tambura). Os dolomitos triássicos estão reduzidos a poucas lentes cataclásticas descontínuas. A nível de detalhe, a estrutura da fase $\mathrm{D}_{1}$ é complicada por 


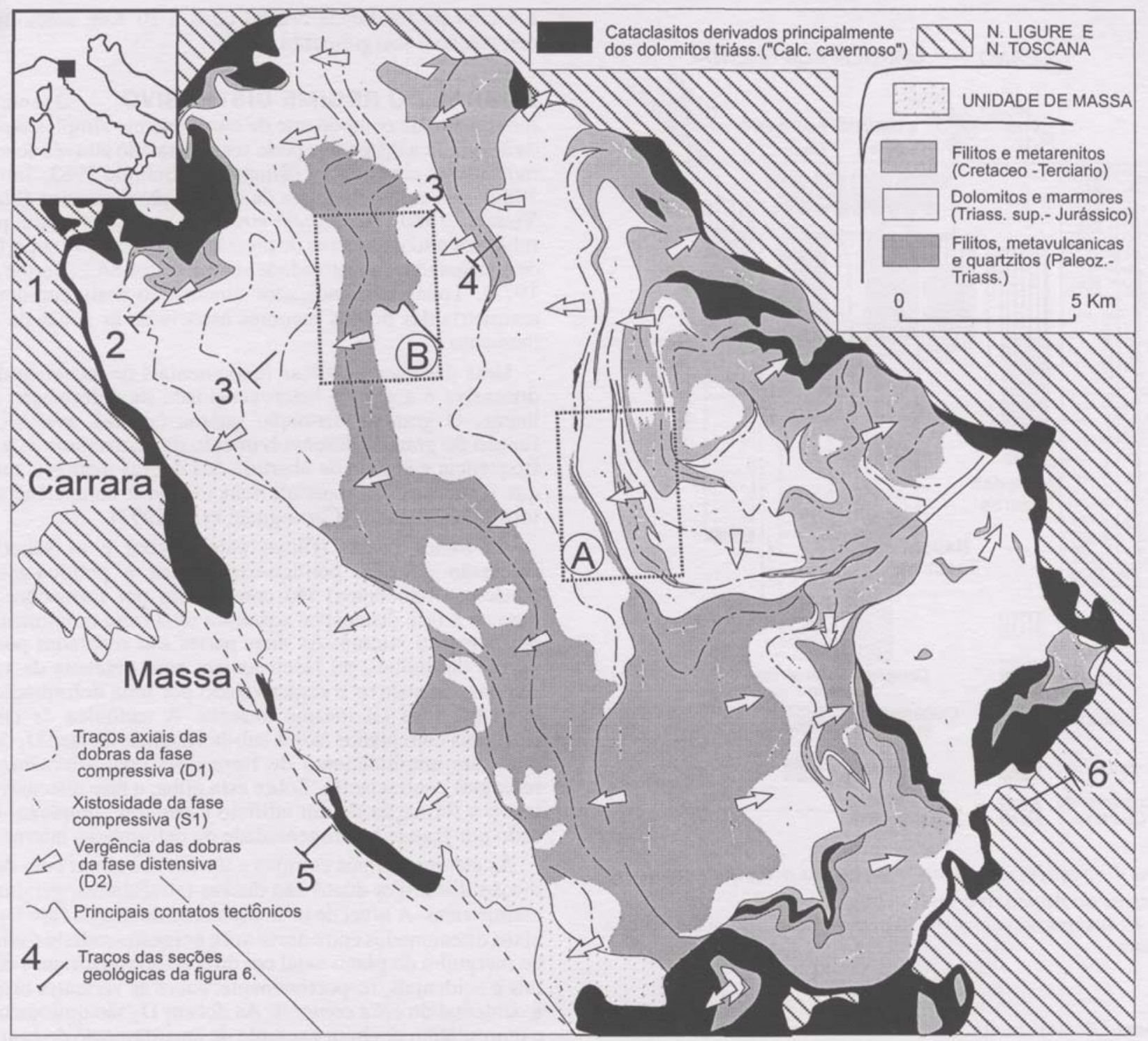

Figura 5 - Esquema da janela tectônica dos Alpes Apuanes. Os retângulos desenhados com linhas tracejadas delimitam as áreas do vale do Arni (A) e do alto vale do Frígido $(B)$.

Figure 5 - Sketch map of Apuane Alps Tectonic Window. Rectangle (A): Arni Valley; Rectangle (B) Upper Frigido Valley

dobras de ordens superiores e cavalgamentos dúcteis, que provocaram numerosas repetições estratigráficas.

A estrutura se estende por cerca de dez quilômetros, e afeta uma faixa que atinge sua máxima amplitude sobre o Monte Fiocca. Vista de sul, a dobra possui a forma de um grande "S", cujo flanco inverso aflora na vertente oriental do vale do Arni, com um comprimento de cerca $1 \mathrm{Km}$, medido ortogonalmente ao eixo. As formações sobrejacentes ao cavalgamento do Monte Tambura não foram envolvidos no dobramento.

A cinemática desta estrutura é coerente com uma grande zona de cisalhamento distensiva,. delimitada no topo pelos dolomitos triássicos do Monte Tambura. Na figura 9 é feita uma restauração da estrutura de interferência do Vale do Arni, assumindo-se que as dobras tardias sejam devidas a uma deformação homogênea, por cisalhamento simples, com transporte para oeste. Subtraindo-se uma deformação cisalhante igual a 3, obtém-se uma estrutura na qual os planos axiais da fase $\mathrm{D}_{1},(\mathrm{~S} 1)$ apresentam uma forma sigmoidal, coerente com uma zona de cisalhamento com transporte para leste. A geometria resultante parece ser originada pelas heterogeneidades do deslocamento e da deformação interna ao longo de uma megafaixa de cisalhamento da fase $\mathrm{D}_{1}$, com transporte para leste. Nas proximidades do Monte Tambura a deformação aumenta, como é evidenciado por lineações de estiramento e xistosidade mais pronunciadas, além de estruturas isoclinais, particularmente achatadas.

A figura 9 mostra, portanto, que a complicada estrutura do Vale do Arni pode ser obtida mediante:

1) Uma deformação cisalhante heterogênea durante a fase $\mathrm{D}_{1}$ (Fig. 9D), com transporte para leste, associada ao cavalgamento do Monte Tambura, posicionado no topo da estrutura; o limite inferior da estrutura não aflora. Apesar da escala, as relações entre os planos axiais das dobras $\sin -\mathrm{D}_{1}$ e o cavalgamento são análogas a estruturas micro-mesoscópicas do tipo S-C (Berthé et al. 1979);

2) Uma deformação cisalhante durante a fase $D_{2}$ (Fig 9 C-B-A), com transporte para oeste. Nesse evento, as variações de atitude do acamamento devido à transposição da fase $\mathrm{D}_{1}$ 


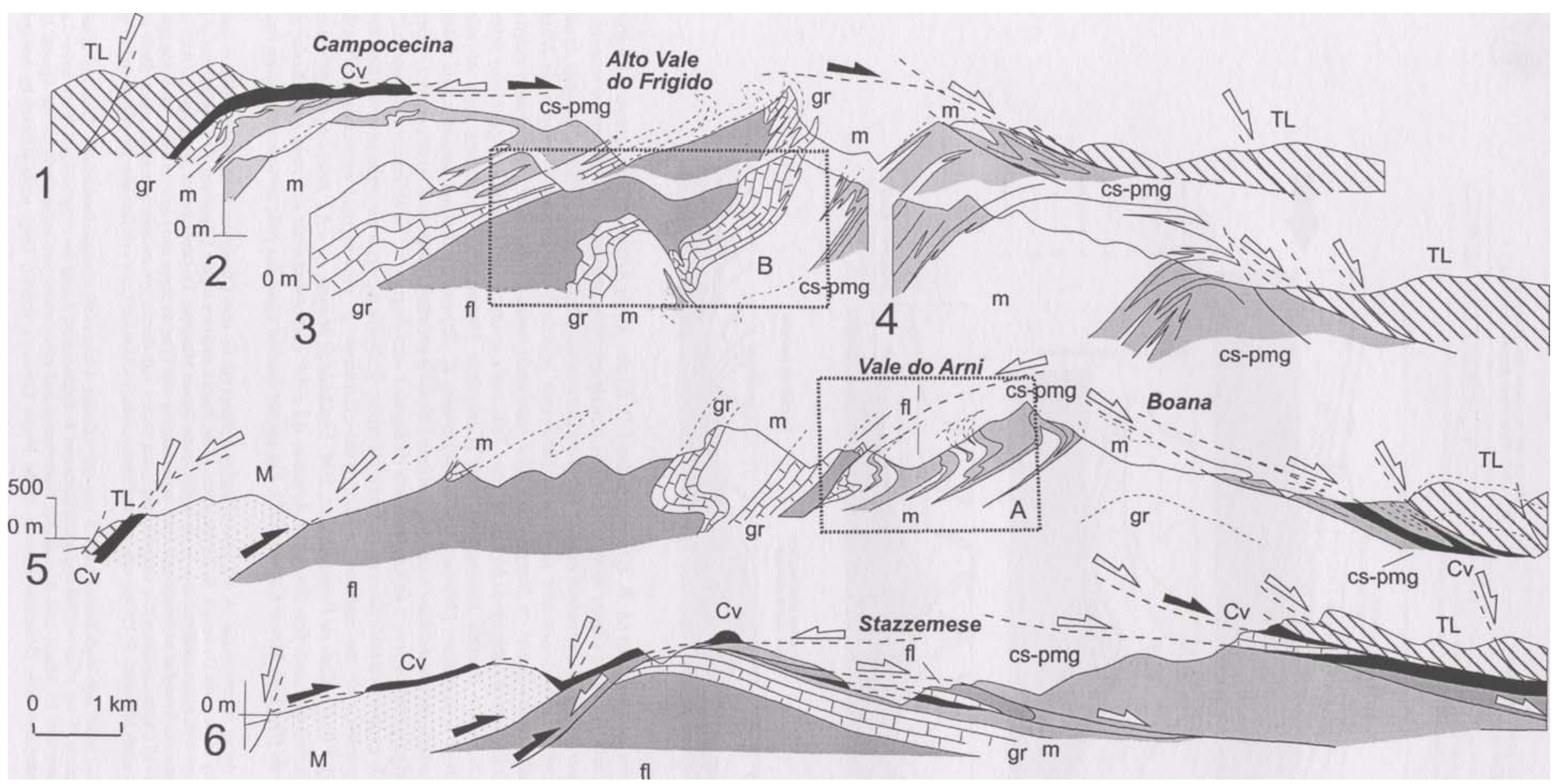

Figura 6 - Secções geológicas esquemáticas da janela tectônica dos Alpes Apuanes, mostrando as posições dos vales do Arni (A) e do Frígido (B), detalhados nas figuras 8 e 10, respectivamente, fl: Filitos e metariolitos do embasamento paleozóico; gr: dolomitos e calcários dolomíticos de idade norica ("Grezzoni"); m: mármores dolomíticos e mármores de Carrara, Liássico inferior; cs-pmg: metacalcários com chert; metaradiolaritos, filitos e metarenitos, Liássicos medio-Oligoceno; cv: cataclasitos derivados principalmente de dolomitos do Triássico superior ("Calcário Cavernoso "); M: Unidade de Massa; TL: Nappe Toscana e Domínio Ligure. As setas negras indicam o movimento durante a fase compressiva $D_{1}$; as setas brancas o movimento durante a fase distensiva $D_{2}$. Observe-se que, na vertente oriental do maciço, $D_{1} e D_{2}$ apresentam a mesma direção de transporte, enquanto na vertente ocidental, apresentam direções opostas. Os traços dessas secções são indicadas na figura 5 . Nos retângulos desenhados em tracejado estão delimitadas as estruturas quilométricas da fase $D_{2}$ no alto vale do Frígido e no vale do Arni, que são discutidas no texto. Figure 6 - Schematic geological sections in the Apuane Alps tectonic window.

fl: schists and metavolcanic rocks of the Paleozoic basement ("Filladi inferiori, Porfiroidi"); gr: dolomites and dolomitic limestones. Norian; m: marbles and dolomitic limestones, lower Liassic; cs-pmg: cherty limestones

("Calcari selciferi"), radiolarites, micaschists and metasandstones. (middle Liassic-Oligocene); cv: cataclastic rocks, mostly derived from upper Triassic dolomites ("Calcare Cavernoso"); M: Massa unit

TL: Tuscan nappe and Ligurian units. Black arrows point to transport directions during collisional tectonics $\left(\mathrm{D}_{1}\right)$, white arrows indicate sense of movement contemporaneous with $\mathrm{D}_{2}$ extension. Note that $\mathrm{D}_{1}$ and $\mathrm{D}_{2}$

transport is the same in the eastern side of the Apua/ie Alps, $D_{1}$ and $D_{2}$ transport are opposite in the western side. 


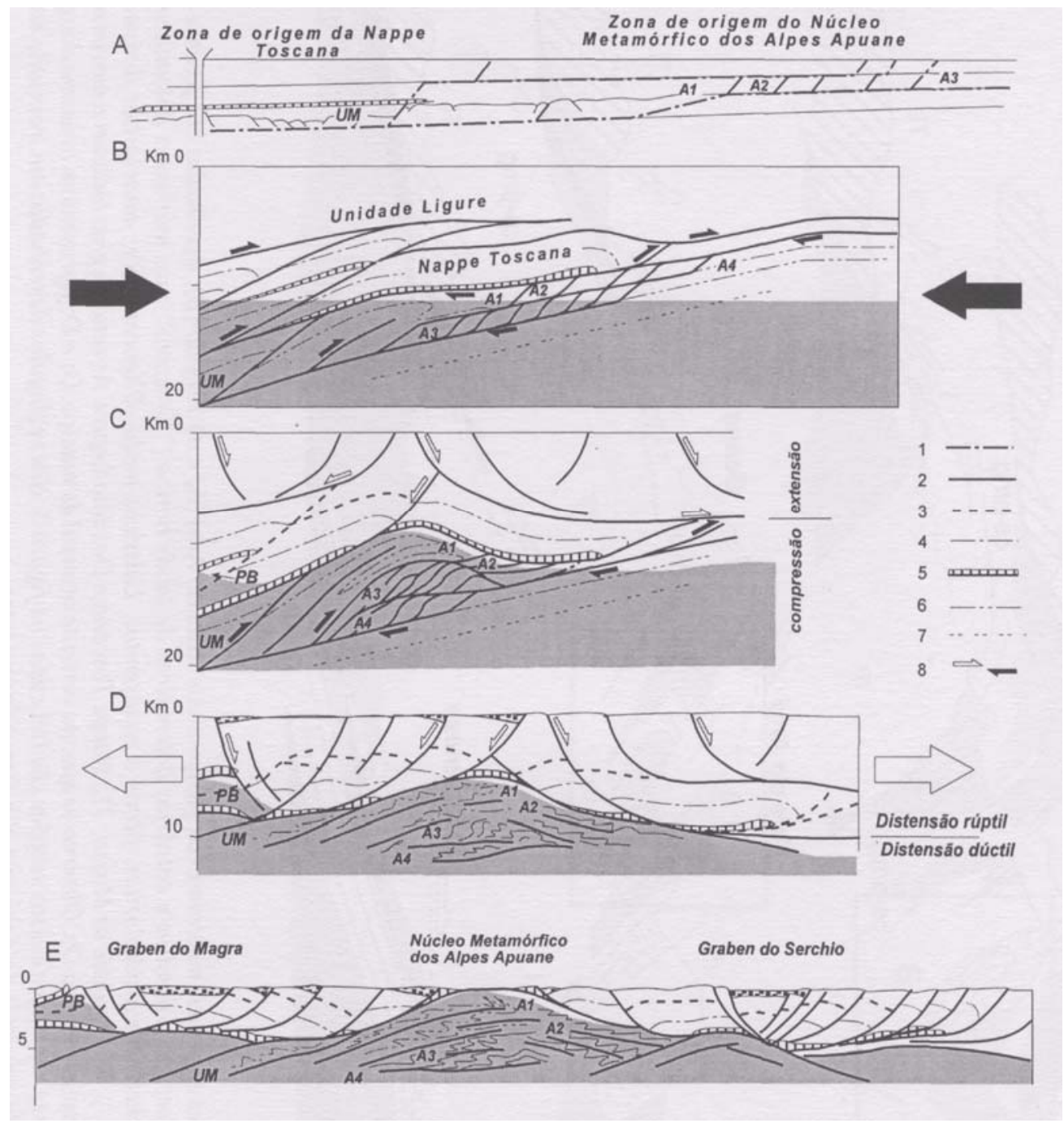

Figura 7 - Esquema da evolução tectônica compressiva $(A, B, C)$ e distensiva ( $D, E$ ) dos Alpes Apuane (Carmignani e Kligfield, 1990, modificado). A: geometria pré-colisão com os traços restaurados dos cavalgamentos principais. B: desenvolvimento do duplex dos Alpes Apuane (Oligoceno Superior). C: desenvolvimento da pilha antiformal no Núcleo Metamórfico dos Alpes Apuane e possível inicio da tectônica distensiva em níveis crustais superiores (Mioceno inferior). D: Desenvolvimento do Núcleo Metamórfico dos Alpes Apuane. O cavalgamento basal da Nappe Toscana é reativado como detachment; este separa extensos setores, principalmente através de falhas lístricas e rotação de blocos (Nappe Toscana e unidades do Domínio Ligure) dos setores em distensão, mediante zonas de cisalhamento dúcteis sin-metamórficas (Complexo Metamórfico Toscano), cuja atitude é determinada pelas estruturas compressivas precedentes (Mioceno médio-superior). E: Exposição dos metamorfitos do Núcleo Metamórfico por denudação tectônica e sorguimento devidos a adelgaçamento crustal e erosão (Plioceno-Pleistoceno). 1: Traços dos cavalgamentos restaurados; 2: cavalgamentos ativos e falhas normais de baixo e alto angulo; 3: cavalgamentos inativos; 4: base da Formação do Macigno (flysch); 5: evaporitos triássicos e brechas tectônicas; 6: limite superior do embasamento hercínico de baixo grau metamórfico; 7: limite superior de um suposto embasamento cristalino; 8: movimentos extensionais (flechas brancas) e contracionais (flechas negras). PB: Unidade de Punta Bianca; UM: Unidade de Massa; A1 e A2: porções sul-ocidentais e norte-orientais, respectivamente, do Núcleo Metamórfico dos Alpes Apuane; A3 e A4: elementos mais externos empilhados sob a pilha antiformal (substrato mesozóico do flysch do Monte Cervarola ?). Em cinza: rochas afetadas pelo metamorfismo de baixo grau terciário.

Figure 7 - Tectonic evolution of the Apuane Alps during compressional (A, B,C) and extensional phases (D, E), after Carmignani \& Kligfield (1990), modified. A: Pre-collisional situation, with restored geometry of the main $\mathrm{D}_{1}$ thrusts. B: Development of the duplex structure (upper Oligocene). C: Development of the antiformal stack geometry, probably conteporaneous with extensional tectonics in the higher levels (lower Miocene). D: Development of the Apuane Alps core complex. The floor thrust of the Tuscan nappe is now reactivated as an extensional fault; in the hanging wall (Tuscan nappe and Ligurian units), extension results from normal faults and block rotation; in the footwall (Apuan metamorphic complex) extension occurs with ductile syn-metamorphic shear zones. Shear zone locations are inherited from $\mathrm{D}_{1}$ structures. (Middle-upper Miocene). E: Present exposures of metamorphic rocks at the Earth's surface after denudation linked with ongoing crustal thinning (Pliocene-Pleistocene).

1- restored thrusts, 2- active thrusts, low-angle normal faults, high-angle normal faults, 3- non-active thrusts. 4-base of the Macigno formation, 5- Triassic evaporites and tectonic breccias, 6- top of the Paleozoic basement, 7- top of an inferred crystalline basement, 8- displacement during the compressional (black arrows) and extensional events (white arrows).PB: Punta Bianca unit; M: Massa unit; Al and A2: southwestern and northeastern part, respectively, of the Apuane Alps metamorphic complex; A3 and A4: external underthrust units (Mesozoic substrata of the Monte Cervarola flysch?) Gray: rocks affected by low-grade metamorphism. 


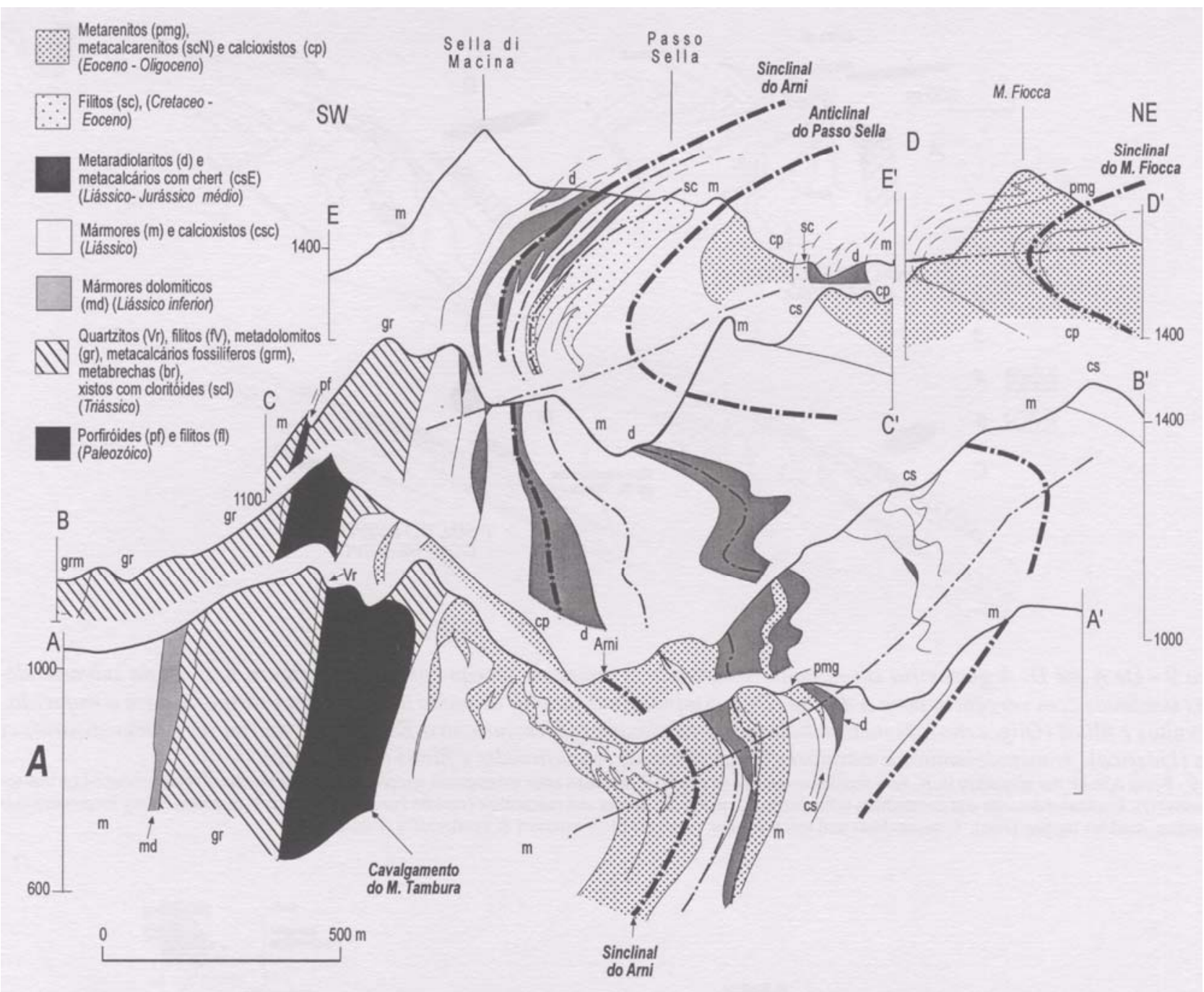

Figura 8 - Secção geológica composta através do Vale do Arni (flanco ocidental do Núcleo Metamórfico dos Alpes Apuane), com vista para Noroeste. O padrão de interferência deve-se à superposição de dobras deitadas $D_{2}$, sobre dobras rompidas $D_{1}$.

Figure 8 - Composite geological profile in the Arni valley (western side of the Apuane Alps core complex, viewing toward Northwest). The structure of the area results from superposed $\mathrm{D}_{2}$ recumbent folds over $\mathrm{D}_{1}$ disrupted folds.

foram amplificadas. Em particular, ao longo da faixa onde o acamamento estava mais inclinado para oeste, este acabou por rotacionar até sua inversão, no final da fase $\mathrm{D}_{1}$.

A estrutura do Alto Vale do Frígido No alto Vale do Frígido aflora outra estrutura de interferência de dimensão quilométrica, entre a tectônica compressiva $\mathrm{D}_{1}$ e a tectônica distensiva $\mathrm{D}_{2}$.O flanco inverso de um grande anticlinal da fase $\mathrm{D}_{1}$ (Anticlinal do Vinca) apresenta-se redobrado por um antiforme com núcleo de mármores liássicos (Antiforme do Monte Rasori) e por um sinforme, em cujo núcleo aparecem filitos paleozóicos (Sinforme do Monte Rasori) (Fig. 10). Estas dobras tardias diferenciam-se das dobras da fase $\mathrm{D}_{2}$ do vale do Arni, tendo em vista que: (l) apresentam planos axiais de forte mergulho, (2) afetam principalmente os dolomitos triássicos, e (3) desaparecem rapidamente, seja para cima ou para baixo. Os flancos normais do Anticlinal do Vinca e do sinclinal subjacente (Sinclinal do Orto di Donna) não estão redobrados.

Os filitos e calcixistos cretáceo-eocênicos do núcleo do Sinclinal do Orto di Donna e os filitos paleozóicos do núcleo do Anticlinal do Vinca sofreram uma forte deformação com vergência para oeste, evidenciada por intenso dobramento a nível de micro e de macro escala, e por uma xistosidade $S_{2}$ penetrativa. Nos filitos cretáceo-eocênicos, esta última pode tornar-se a superfície mais evidente em afloramento. Os núcleos das dobras funcionaram como zonas de cisalhamento extensionais durante a fase distensiva $\mathrm{D}_{2}$ (ver Fig. $11 \mathrm{~A}$ ).

$\mathrm{O}$ deslocamento em direção oeste, sofrido pelo núcleo incompetente do Sinclinal do Orto di Donna, e as eventuais falhas dúcteis, exaurem seus respectivos rejeitos no mesmo sentido, devido ao fechamento das formações incompetentes na charneira da referida sinclinal. Contrariamente, os filitos do núcleo do Anticlinal do Vinca, abrindo-se progressivamente em direção oeste, permitem que, no mesmo sentido, aumente o deslocamento por deformação interna e por falhas extensionais dúcteis de baixo ângulo. Um dispositivo cinemático desse tipo é esquematizado na figura $11 \mathrm{~A}$.

A transferência do deslocamento para cima, e na direção do movimento, gerou uma forte componente compressiva paralela à estratificação dos dolomitos do flanco inverso do Anticlinal do Vinca, desenvolvendo-se, assim, dobras flexurais aproximadamente simétricas, nucleadas na zona boudinada da fase $D_{1}$.

A incipiente vergência para oeste, seja do Antiforme, seja do Sinforme do Monte Rasori é devida possivelmente a uma 


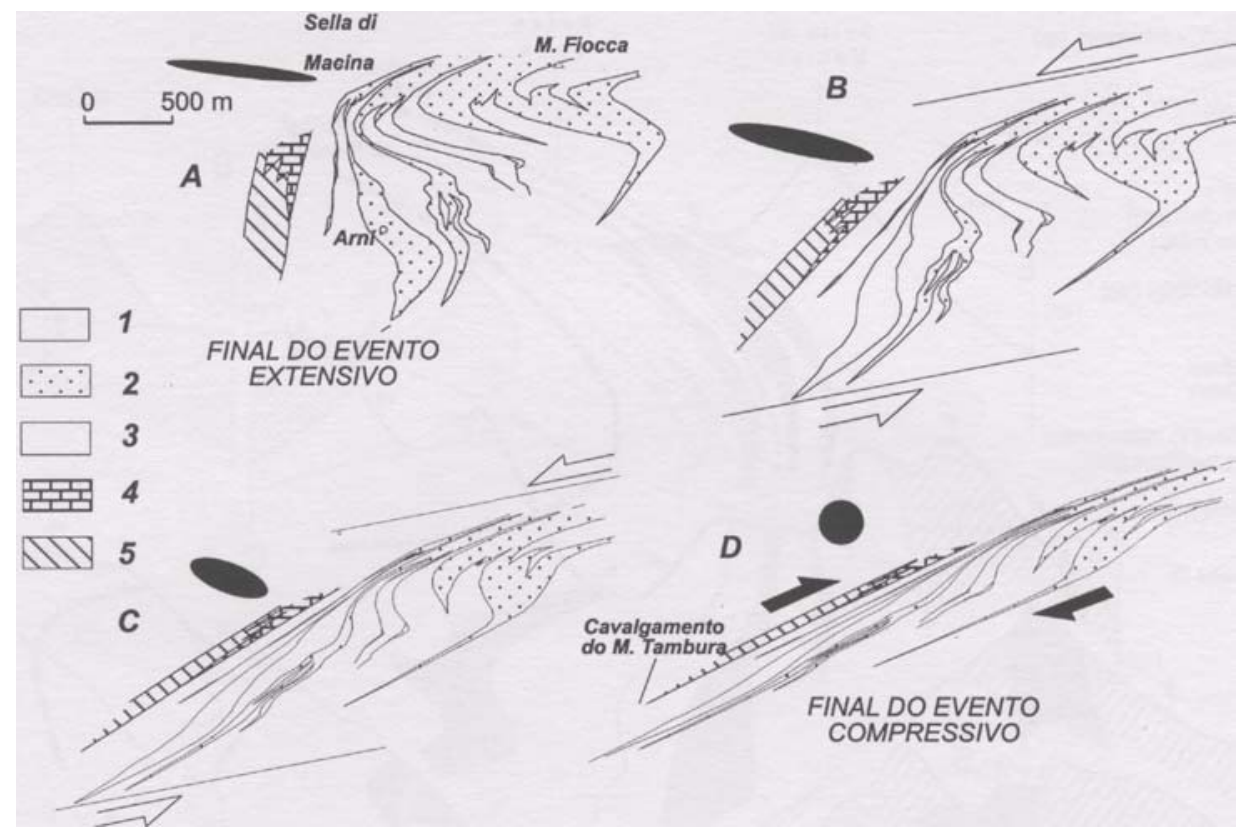

Figura 9 - De A até D: A geometria em A, muito semelhante afigura da secção composta da figura 8, é obtida submetendo-se dobras isoclinais com vergência para a direita (D) a cisalhamento simples de baixo angulo, com transporte para a esquerda. 1 : metarenitos efilitos (Oligoceno); 2: metaradiolaritos e calcioxistos (Mesojurássico-Eoceno); 3: mármores e metacalcários com cherts (Liássico); 4: metadolomitos e mármores (Neotriássico); 5: porfiróides efilitos (Paleozóico).

Figure 9 - From A to D: the geometry in A, very similar to the one in Fig. 8, is obtained after extensional simple shearing of isoclinal folds produced by top-to-the east thrusts (D). 1: metasandstones and micaschists (Oligocene); 2: metaradiolarites and calcschists (middle Jurassic-Eocene); 3: marbles, cherty limestones (Lias); 4: dolomites, marbles (upper Trias); 5: micaschists and metavolcanic rocks ("Filladi inferiori \& Porfiroidi") (Paleozoic).

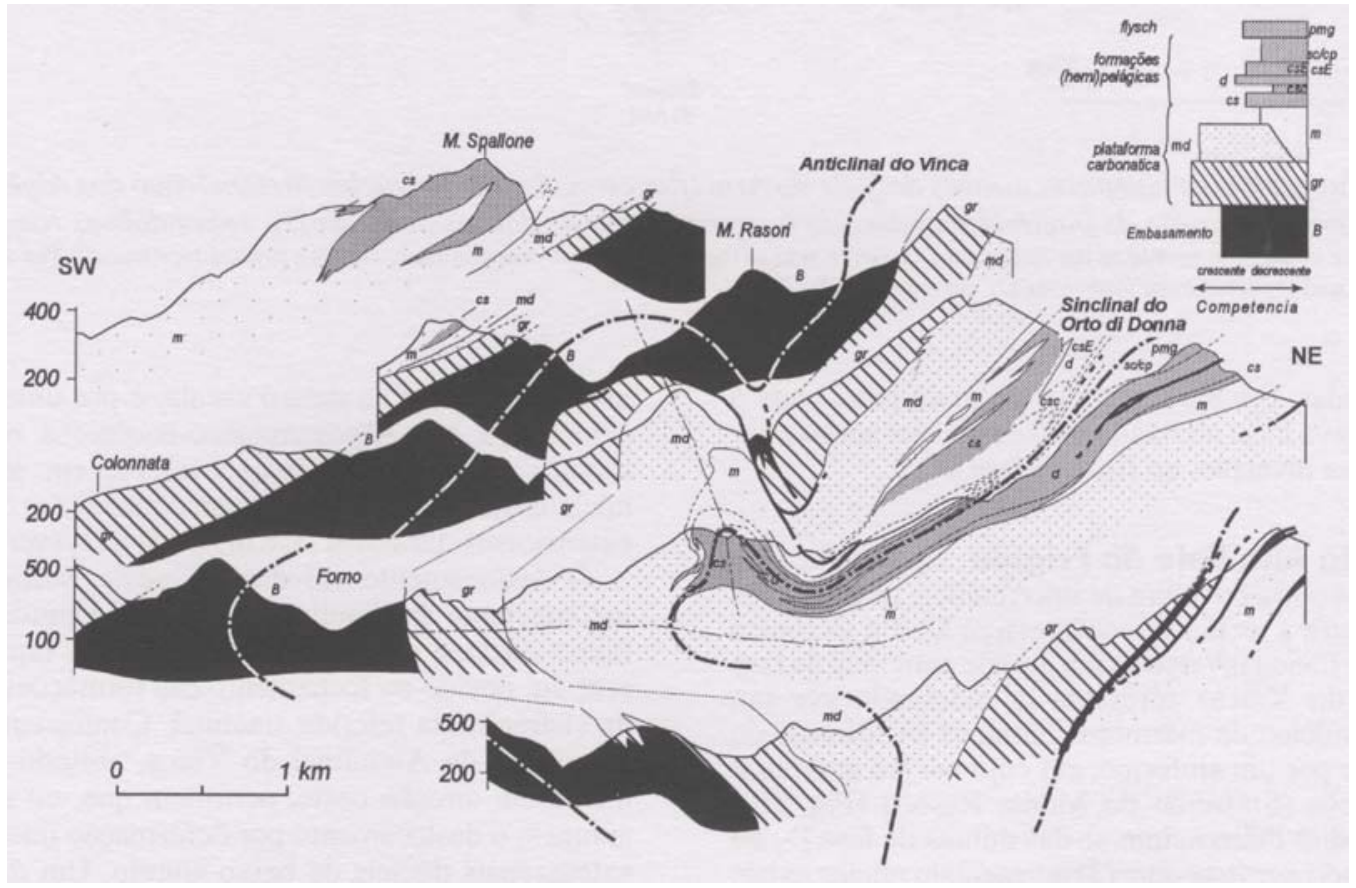

Figura 10 - Secção geológica composta através do Vale do Frígido. B: embasamento paleozóico; gr: dolomitos (Neo-Triássico); md: mármores dolomíticos (Liássico inferior); cs: metacalcários com chert (Meso a Neoliássico); esc: calcioxistos (Liássico superior-Jurássico médio); d: metaradiolaritos (Jurássico superior); CsM: metacalcários chertosos com crinóides (Paleocretáceo); sc/cp: filitos e calcioxistos (Cretáceo-Eoceno); pmg: metaarenitos efilitos (Neo-Oligoceno).

Em linhas com traços e pontos são indicados os traços axiais das dobras da primeira fase.

Figure 10 - Composite geological profile in the Frigido valley. B: Paleozoic basement, gr: dolomites (late Triassic); cs: cherty limestones (meso-Iate Liassic); esc: calcschists (upper Liassic-middle Jurassic); d: radiolarites (upper Jurassic); CsM: cherty crinoidal limestones (early Cretaceous); sc,cp: calcschists and slates (late Oligocene).Point-dotted are axial plane fold traces of $\mathrm{D}_{1}$ folds. 

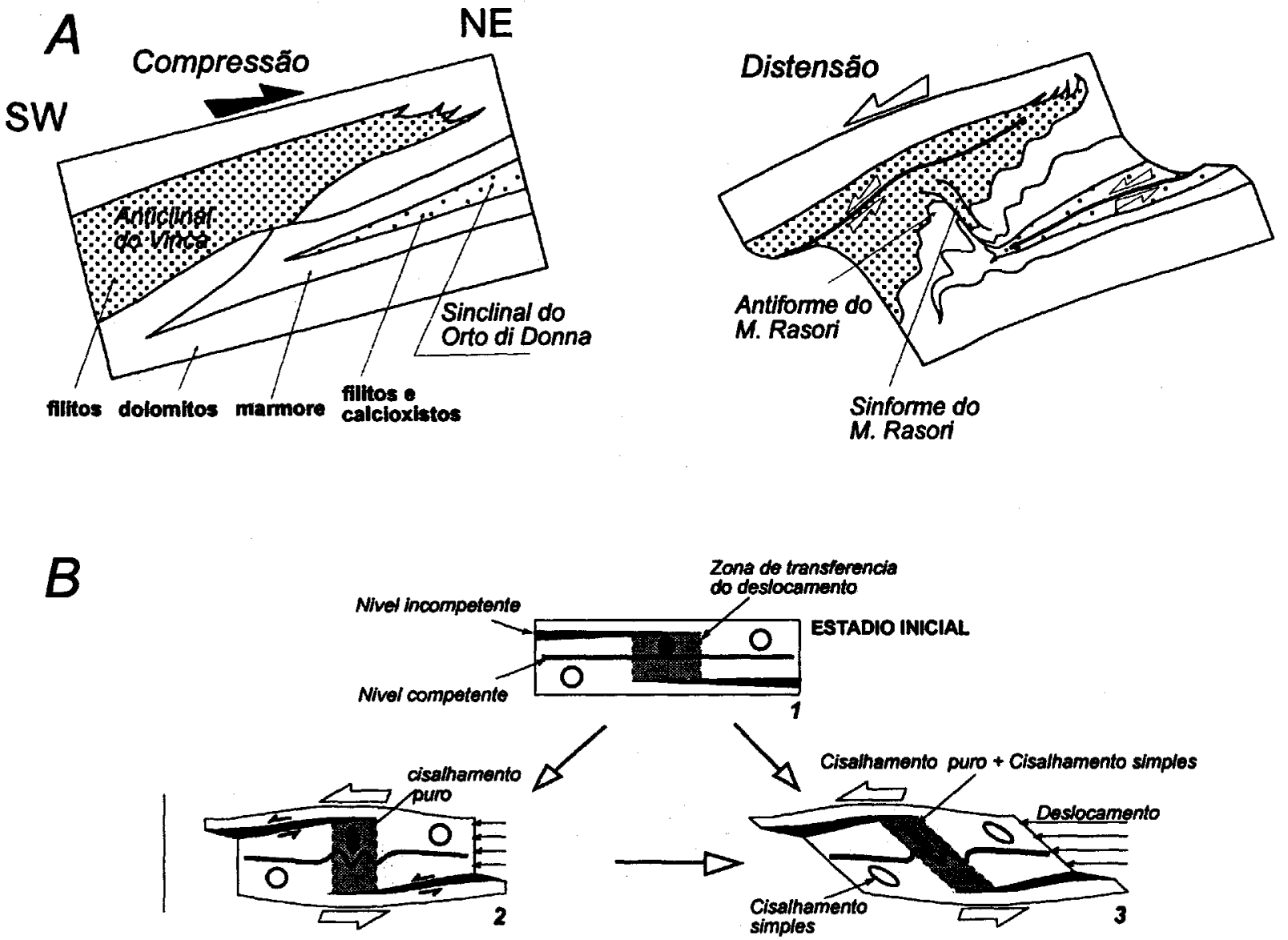

Figura 11 - A-Interpretação da estrutura de interferência do alto Vale do Frigido. As estruturas da segunda fase que afetaram o flanco invertido do anticlinal do Vinca, de primeira fase, são interpretadas como dobras devidas à transferência do deslocamento que afeta os dolomitos triássicos compreendidos entre as duas zonas de cisalhamento dúctil, representadas pelos filitos paleozóicos desenvolvimento de dobras Vinca e por calcioxistos e filitos do núcleo da sinclinal do Orto di Donna. B- Esquema do Figure 11 - A: Interference structures of tas à transferência do deslocamento (Rykkelid \& Fossen, 1991, modificado).

affecting the Triassic dolomitic formations. $D_{2}$ transfer folds anticline (Paleozoic micaschist outcrop) and the second one in the between two km-scale $D_{2}$ shear zones, the first one developed in the core of the $D_{1}$ Vinca Rykkelid \& Fossen, 1991, modified).

componente de cisalhamento simples com transporte para oeste, que afeta a estrutura inteira segundo o mecanismo ilustrado na figura 11B (Rykkelid \& Fossen 1991). Da mesma forma, a diferença entre o flanco oriental do antiforme, uniformemente inclinado para leste, e o seu flanco ocidental, deformado por dobras com planos axiais subhorizontais, é devida a uma componente de cisalhamento simples, segundo o esquema ilustrado na mesma figura 11 .

CONCLUSÕES Nos últimos vinte anos foram publicados numerosos trabalhos sobre dobras associadas a encurtamento crustal. As contribuições mais importantes advêm da aplicação sistemática da análise estrutural às complexas estruturas de interferência em terrenos metamórficos e às secções balanceadas nos complexos de cavalgamento (thrust complex).

Ainda que os trabalhos sobre estruturas associadas a deformações dúcteis extensionais estejam atualmente crescendo de modo exponencial, pouca atenção tem sido dada às dobras associadas à distensão crustal, especialmente aquelas de grandes dimensões. Numerosas estruturas, quais sejam xistosi- dade, lineações de estiramento, dobras, etc., foram desde muito tempo, tacitamente, consideradas exclusivas de setores onde a crosta sofreu encurtamento e espessamento (tectônica compressiva), enquanto à tectônica distensiva eram relacionadas somente estruturas características da distensão de níveis crustais superiores quais sejam, falhas normais, fraturas de extensão, e outras. Em um contexto distensivo, reluta-se em aceitar a existência de dobras inversas quilométricas, que implicam em encurtamentos importantes das superfícies dobradas.

A tectônica distensiva dúctil dos Alpes Apuanes foi reconhecida em um perfil de pelo menos $20 \mathrm{~km}$ de extensão (Fig.6) e, por isto, reflete um razoável adelgaçamento da crosta. Os exemplos descritos neste trabalho demonstram que dobras simétricas, assimétricas, inversas e deitadas de todas as dimensões, inclusive quilométricas, podem estar associadas a zonas de cisalhamento extensionais. Este fato impõe a máxima prudência ao se fazer considerações sobre a tectônica, na escala regional ou crustal, a partir de observações na escala de afloramento ou na escala quilométrica. 
As condições excepcionais de afloramento dos Alpes Apuanes, permitiram evidenciar dobras inversas de dimensões quilométricas, formadas em zonas de cisalhamento extensionais meso-crustais. Estruturas similares foram reportadas em orógenos mais antigos (por ex. no embasamento hercínico da Sardenha) e algumas evidências parecem existir nas rochas do Cinturão Ribeira (Sudeste do Brasil), ainda mais antigo. É possível que as associações de dobras inversas de grandes dimensões, associadas a uma tectônica distensiva, não seja um fenômeno incomum.

Agradecimentos Esta pesquisa foi financiada pela MURST (40\%), CNR (Consiglio Nazionale delle Ricerche) e CNPq (Projeto Bilateral Brasil - Itália)

\section{REFERÊNCIAS}

BERTHÉ D., CHOUKROUNE P. \& CAPAIS D. 1979. Orientations preferentielles du quartz et prthogneissification progressive en regime cisaillant: L'exemple du cisaillement sudarmorican. Buli. Mineral., 102:265-272.

BERTINI, G., CAMELI, G.M., COSTANTINI, A., DECANDIA, F.A., D1 FILIPPO, M.,DINI, L, ELTER, F.M., LAZZAROTTO, A., LIOTTA, D., PANDELI, E., SANDRELLI, F. \& TORO, B. 1991. Struttura geológica fra $\mathrm{i}$ monti di Campiglia e Rapolano Terme (Toscana meridionale): stato attuale delle conoscenze e problematiche. Studi Geologici Camerti, vol. spec. 1:155-178.

BOCCALETTI M. \& GOSSO G. 1980. Analisi delia deformazione plicativa e rapporti con Io sviluppo delia blastesi metamorfica nell' área di Campocecina-M. Pisanino delle Alpi Apuane Settentrionali. Mem. Soc.Geol.lt., 21:101-110.

BOCCALETTI, M. \& GUAZZONE, G. 1974. Remnant arcs and marginal basins in the Cenozoic development of the Mediterranean. Nature, 252:54-78.

Carmignani L. \& Kligfield R. 1990. The transition from compression to extension in mountain belts: evidence from the Northern Apennines Core Complex. Tectonics, 9:1275-1303.

CARMIGNANI L., FANTOZZI P.L. \& MECCHERIM. 1993. La vergenza "sin-" e "postnappe" delia Falda Toscana neile strutturedi Pescaglia e di Castelpoggio (Alpi Apuane). Boll. Soc.GeoL It., 110:351-364.

CARMIGNANI L., GIGLIA G. \& KLIGFIELD R. 1980. Nuovi dati sulla zona di taglio ensialica delle Alpi Apuane. Mem. Soc. Geol. It., 21:93-100.

CERRINA FERONI, A., PLESI, G. LEONI, L. \& MARTINELLI, P. 1983. Contributo alia conoscenza dei processi metamorfici di grado molto basso (anchimetamorftsmo) a carico della Falda Toscana nell'area di ricoprimento apuano. Boll. Soc. Geol. It., 102:269-280

CONEY P.J. \& HARMS T. 1984. Cordilleran metamorphic core complex: Cenozoic extensional relicts of Mesozoic compression. Geology, 12:550-554.

DAVIS G.H. 1980. Structural characteristics of metamorphic core complexes, southern Arizona. In: Cordilleran Metamorphic Core Complexes, edited by M. Crittenden, P. CONEY \& G.H. DAVIS.W. Mem. Geol. Soc. Am., 153:35-78.

ELTER, P., GIGLIA, G., TONGIORGI, M. \& TREVISAN, L. 1975. Tensional and compressional areas in the recent (Tortonian to present) evolution of the Northern Apennines. Boll. Geof. Teor. Appl., 42:3-18.

GIGLIA G. \& RADICATI DI BROZOLO R. 1970. K/Ar age of metamorphism in the Apuane Alps (northern Tuscany). Boll. Soc. Geol. It., 89:485-497

KLIGFIELD R., HUNZIKER J., DALLMEYER R.D. \& SCHAMEL S. 1986. Dating of deformation phases using K-Ar and $40 \mathrm{Ar} / 39 \mathrm{Ar}$ techniques: Results from Northern Apennines. J. Struct. Geol., 8:781-798.

LAVECCHIA, G. 1988. The Tyrrhenian-Apennines system: structural setting and seismotectogenesis. Tectonophysics, 147:263-296.
LISTER G. \& DAVIS. G.A. 1989. The origin of metamorphic core complexes and detachment faults formed during Tertiary continental extension in the northern Colorado River region. U.S.A.. J Struct. Geol., 11:65-94.

LOCARDI, E. 1982. Individuazione delle strutture sismogenetiche daU'esame dell'evoluzione vulcano-tettonica dell'Appennino e del Tirreno. Mem. Soc. Geol. It., 24:569-596.

MALAVIELLE J. 1987. Kinematics of compressional and extensional ductile shearing deformation in a metamorphic core complex of the northeastern Basin and Range. J. Struct. Geol., 9:541-554.

MALINVERNO, A. \& RYAN, W.B.F. 1986. Extension in the Tyrrhenian Sea and shortening in the Apennines as result of arc migration driven by sinking of the lithosphere. Tectonics, 5:227-246.

MERLA.G. 1952. Geologia dell'Appenninno settentrionale. Boll Soc. Geol. It. 70:95-382.

PATACCA E. \& SCANDONE P. 1989. Post-Tprtonian mountain building in the Apennines. The role of the passive sinking of a relic lithospheric slab. In: The Lithosphere In Italy (Boriani et al., Eds.), Atti dei Convegni Lincei, 80:157-186.

PLATT J. \& VISSER R. 1980. Extensional structures in anisotropic rocks. J. Struct. Geol., 2:397-410.

PLATT J. 1986. Dynamics of erogenic wedges and uplift of high-pressure metamorphic rocks. Geol. Soc. Am. Bull., 97:1037-1053.

RYKKELID E. \& FOSSEN H. 1992. Composite fabrics in mid-crustal gneisses: observations from the Oygarden Complex, West Norway Caledonides. J. Struct. Geol., 14:1-9.

ROYDEN, L, PATACCA, E., \& SCANDONE, P. 1987. Segmentation and configuration of subducted lithosphere in Italy: an important control on thrust belt and foredeep basin evolution. Geology, 15:714-717.

SCANDONE, P. 1979. Origin of the Tyrrhenian Sea and Calabrian arc. Boll. Soc. Geol. It., 98:27-34

SERRI G., INNOCENTIF., MANETTI P., TONARINI S. \& FERRARA G. 1991. II magmatismp neogenico-quaternario dell'area tosco-laziale-umbra: implicazioni sui modelli di evoluzione geodinamica dell'Appennino settentrionale. Studi Geologici Camerti, vol. spec. 1:429-463.

SIMPSON C. \& SCHMID S. 1983. An evaluation of criteria to deduce the sense of moviment in sheared rocks. Geol. Soc. Am. Bull., 94:1281-1288.

SIMPSON C. 1986. Determination of moviment sense in mylonites. J. Geol. Educ.,34:246-261.

VAN BEMMELEN, R. 1972. Driving forces of Mediterranean orogeny. Test case I: Tyrrhenian area. Geol. Mijnbouw, 51:548-573.

WEZEL, F. 1982. The Tyrrhenian Sea: a rifted krikogenic-swell basin. Mem. Soc. Geol. It., 24:531-568.

Manuscrito A846

Recebido em 27 de maio de 1996

Revisão do autor en 28 de setembro de 19\% Revisão aceita em 30 de setembro de 19\% 